\title{
Induced Positron Annihilation Investigation of Cadmium Zinc Telluride Crystal Microstructures
}

Douglas W. Akers Joel Wenzinger

June 2005

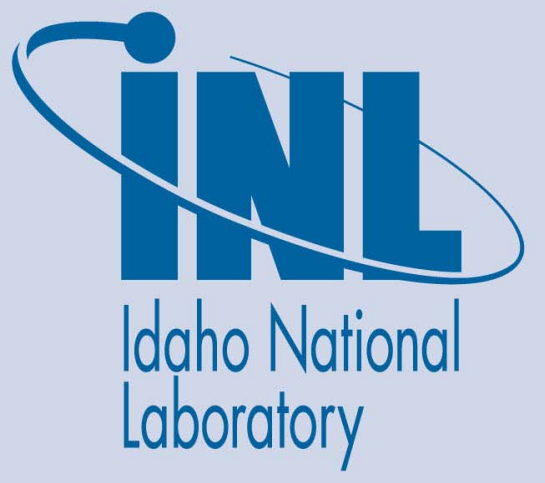

The INL is a U.S. Department of Energy National Laboratory operated by Battelle Energy Alliance 
INL/EXT-05-00397

\title{
Induced Positron Annihilation Investigation of Cadmium Zinc Telluride Crystal Microstructures
}

\author{
Douglas W. Akers ${ }^{a}$
}

Joel Wenzinger ${ }^{b}$

${ }^{\mathrm{a}}$ INL

${ }^{\mathrm{b}}$ Positron Systems, Inc.

June 2005

\section{Idaho National Laboratory \\ Idaho Falls, Idaho 83415}




\begin{abstract}
Cadmium-Zinc-Telluride (CZT) crystals are used in semiconductor radiation detectors for the detection of $\mathrm{x}$-ray and gamma radiation. However, production of detector grade crystals is difficult as small variations in compositional uniformity and primarily the zinc content can significantly affect the ability of the CZT crystal to function as a radiation detector. Currently there are no known nondestructive methods that can be used to identify detector grade crystals. The current test method is to fabricate and test the detector to determine if the crystal is sufficiently uniform and of the correct composition to be considered a detector grade crystal. Consequently, nondestructive detection methods are needed to identify detector grade crystals prior to the fabrication process. The purpose of this feasibility study was to perform a preliminary assessment of the ability of several new, nondestructive technologies based on Induced Positron Annihilation (IPA) to determine if detector grade CZT crystals can be identified. Results of measurements performed on specimens from Fisk University and EV Products, Inc. indicate that both the near surface Distributed Source Positron Annihilation (up to $3 \mathrm{~mm}$ penetration) and the volumetric Photon Induced Positron Annihilation methods may be suitable for determining CZT crystal quality. Further work on CZT crystals with a broader range of compositions and detector characteristics is needed to provide a well defined, calibrated, method for assessing CZT crystal quality.
\end{abstract}




\section{SUMMARY}

Cadmium zinc telluride (CZT) crystals are used for semiconductor radiation detectors in a broad range of applications ranging from basic science to national security applications. Being a ternary compound complicates the manufacturing process, because compositional nonuniformity is intrinsic to the Bridgman crystal growth techniques used. Induced Positron Annihilation (IPA) measurements were performed on a series of CZT radiation detector crystals with differing compositions and detector characteristics. The purpose of these measurements was to assess the ability of the IPA technologies, Photon Induced Positron Annihilation (PIPA) and Distributed Source Positron Annihilation (DSPA) to nondestructively detect variations in the CZT microstructure that affect the ability of CZT crystals to function as detectors. Measurements were performed on crystals provided by Fisk University, and EV Products, a commercial vendor of CZT detectors.

The PIPA volumetric measurement process produces positron emitters through the entire thickness of the material measured thereby producing an in situ positron source that can be used to assess the microstructure of the material being examined at the atomic lattice structure level. This technique produces a unique numerical material "signature" that can be measured very precisely $(\sim 0.1 \%)$. This technique, developed at the Idaho National Laboratory has demonstrated the capability to detect variations in material microstructure in a broad range of materials ranging from polymers to nickel superalloys

The DSPA process measures microstructural variations in the top 1-5 $\mathrm{mm}$ of a material depending on the density of the material measured. The DSPA positron production source is created by bombarding a suitable material (e.g., copper) with high-energy X-rays, which produce neutron deficient nuclei that decay through positron emission and produce positrons with high energies (2.92 MeV for copper). The DSPA source can be configured as a probe $(0.25$ $\mathrm{cm}^{2}$ ) or up to a $10 \mathrm{~cm}^{2}$ distributed source for the characterization of large surface areas. This technique has been used on a broad range of near surface material defect issues ranging from surface barrier coatings to corrosion and shot peening.

Results of the PIPA and DSPA measurements performed on the Fisk University crystals indicated that the DSPA near surface process is able to easily discriminate between a detector grade specimen, CZT-3, and a larger non detector grade section of a crystal. The difference in DSPA response was statistically significant and indicated that crystal differences can be measured nondestructively. However, the volumetric PIPA measurements on both crystals produced similar results suggesting no volumetric differences in the microstructure of the crystal specimens. Fisk University is planning additional destructive measurements for comparison with the IPA measurements

Measurements were performed on specimens of CZT crystals with known detector characteristics that were obtained from EV Products, Inc., which manufacturers CZT crystals. Results of both the near surface and volumetric measurements clearly indicated the ability of these methods to discriminate between detector grade and nondetector grade crystals. The PIPA volumetric technique appeared to be most sensitive to differences in detector quality. 
The PIPA and DSPA measurements performed on the CZT crystals from Fisk University and EV Products were initial feasibility measurements performed to assess crystal quality for the range of specimens and crystal characteristics provided by these groups. The crystals provided had a limited range of known microstructural variations and characteristics. The results of this preliminary feasibility study suggest that the IPA techniques have promise as nondestructive methods for accurately and precisely quantifying CZT detector quality. Further IPA and DSPA measurements are needed 1) to verify the results of the current feasibility measurement results, 2) to assess CZT crystals with a broader range of microstructural characteristics, and 3) to provide sufficient data to optimize the IPA techniques for discriminating differences in CZT crystal microstructural characteristics. 


\section{ACKNOWLEDGMENTS}

Specific acknowledgements for this work go to Dr Arnold Burger of Fisk University, Alan Hunt of Idaho State University and Dr. Csaba Szeles, Principal Scientist and Manager of R\&D and Crystal Growth Operations at EV Products, for providing insight and their knowledge of CZT crystal growth and issues. 


\section{CONTENTS}

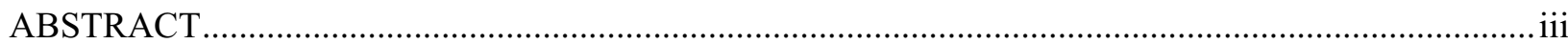

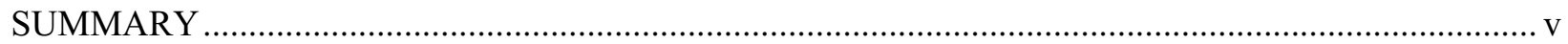

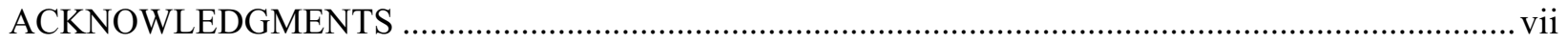

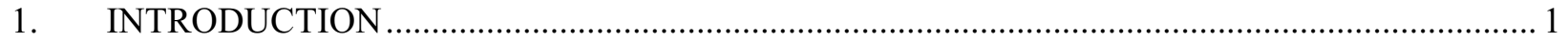

2. INDUCED POSITRON ANNIHILATION TECHNOLOGY …............................................ 1

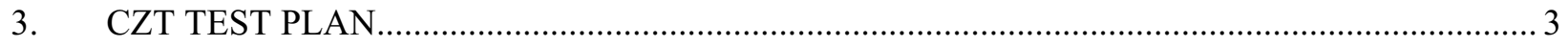

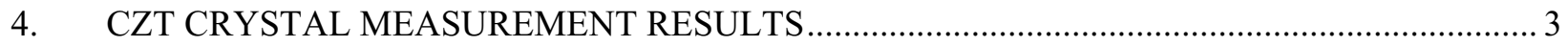

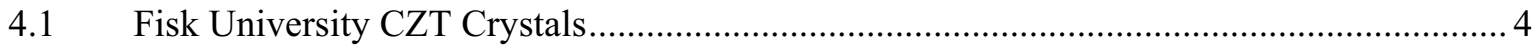

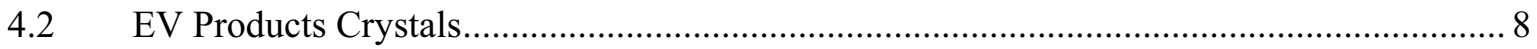

\section{FIGURES}

1. Resolved defect sizes for positron spectroscopy relative to other technologies ............................ 2

2. Measurable defect concentrations for positron spectroscopy relative to other technologies ............. 2

3A. Fisk University boule section (not detector grade) …................................................................ 4

3B. Fisk University boule section - expanded view (not detector grade) …...................................... 5

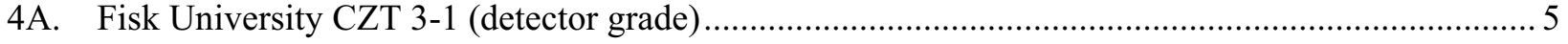

4B. Fisk University CZT 3-1 (detector grade) - expanded view ................................................... 6

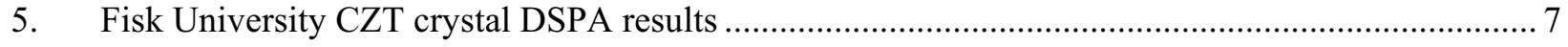

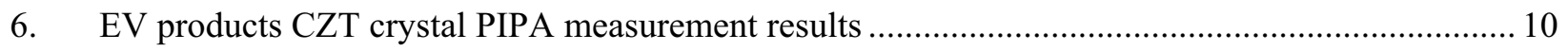

A-1. The three most common experimental positron techniques for measuring electron momentum are (a) angular correlation of annihilation radiation, (b) doppler broadening, and (c) positron lifetime

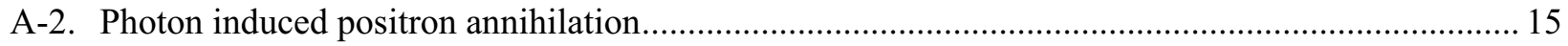

A-3. Doppler broadening analysis for the S parameter ................................................................ 16

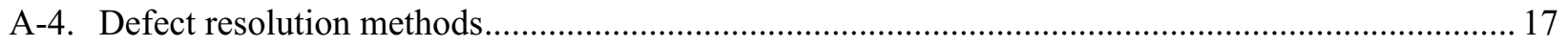

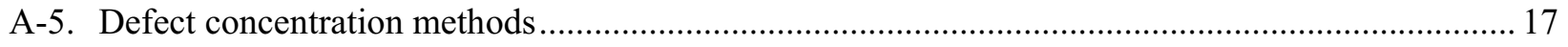




\section{TABLES}

1. CZT crystal dimensions and detector characteristics .................................................................. 3

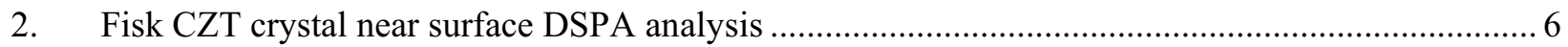

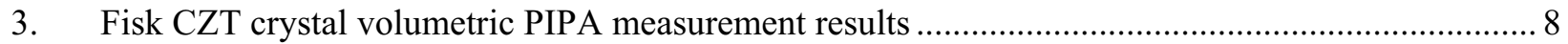

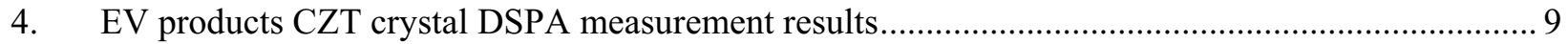

5. EV products CZT crystal PIPA measurement results .............................................................. 9

B-1. Fisk and Idaho State University CZT crystal DSPA measurement results .................................2 21

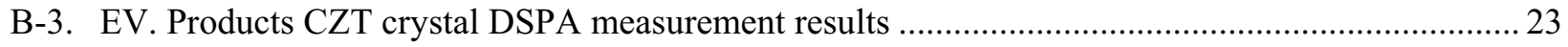

B-4. EV products CZT crystal PIPA measurement results ............................................................... 24 


\title{
Induced Positron Annihilation Investigation of Cadmium Zinc Telluride Crystal Microstructures
}

\author{
1. INTRODUCTION
}

Small variations in the ternary cadmium zinc telluride $\left(\mathrm{Cd}_{1-x} \mathrm{Zn}_{\times} \mathrm{Te}\right)$ elemental ratio and primarily variations in the zinc content of the compound result in the formation of CZT crystals that may or may not be suitable for use as room temperature semiconductor detectors. Small variations in the Bridgman crystal growth process can result in either good quality detector grade crystals or material unsuitable for use as a detector. Currently there are no nondestructive inspection methods capable of determining whether individual CZT crystals are detector grade prior to attaching contacts and testing the crystals as detectors. This results in significant additional costs to detector manufacturers and delays in the crystal manufacturing process. The purpose of this feasibility study was to evaluate the abilities of the Induced Positron Annihilation (IPA) technologies to nondestructively assess defect characteristics in both bulk CZT material and in crystals that were identified and tested as having either "poor" or "good" semiconductor detector characteristics. Samples for this program were obtained from Fisk University, Idaho State University, and EV Products, a commercial manufacturer of CZT detectors. The following sections present a description of the IPA technologies used for the CZT measurements followed by the sample test plan and results of the measurements performed.

\section{INDUCED POSITRON ANNIHILATION TECHNOLOGY}

The IPA technology is composed of two primary measurement methods; Photon Induced Positron Annihilation (PIPA) and Distributed Source Positron Annihilation (DSPA). The PIPA technology utilizes a small 18-20 MV linear accelerator similar to those used for radiation oncology. The PIPA process produces positron emitters throughout the material thereby producing an in situ positron source that can be used to assess the microstructure of the material being examined at the atomic lattice structure level. Since the positrons are being produced in the material itself, the response is a nanoscale measurement response that produces a unique material "signature" that can be measured very precisely $(\sim 0.1 \%)$ and used to separate and identify the microstructure of materials with different characteristics or that have been subjected to different operational or damage effects. This technology along with the DSPA technique is described in more detail in Appendix A.

The DSPA process measures microstructural variations in the top 1-5 $\mathrm{mm}$ of a material depending on the density of the material measured. An activated DSPA measurement source is created by bombarding a suitable material (e.g., a copper foil) with high-energy X-rays, causing a neutron to be ejected from a small number of atoms within the material via a photo-neutron reaction. The neutron deficient nuclei then decay over time and during the decay process produce positrons with relatively high energies $(2.92 \mathrm{MeV})$. With this high positron energy, the DSPA source can be used to penetrate up to 5 $\mathrm{mm}$ into a material depending on its density. The DSPA probe can be configured to almost any shape to provide minimal to no impact on the inspection technique caused by complex component geometries.

Figure 1 shows the resolvable defect sizes for the IPA technologies as compared to standard destructive techniques. This figure, developed by Lawrence Livermore National Laboratory (LLNL), was primarily used to assess surface positron beam techniques and shows the resolved depth penetration up to $1 \mathrm{~mm}$ for the positron beam method. The IPA technologies have a greater depth of penetration than do positron beam methods. The PIPA technique produces a response from through the entire thickness of the material being measured up to about $5 \mathrm{~cm}$ in steel, which is the depth of material that the positron annihilation gamma rays can penetrate without significant attenuation. The DSPA high energy positron sources can be used in a range of configurations and provides better depth penetration than do the beam techniques. 
Figure 2 shows the measurable defect concentrations relative to other measurement technologies. The ability of the positron measurement technology to measure the range of defect concentrations and sizes as indicated in Figures 1 and 2 combined with the IPA technologies ability to perform near surface and volumetric measurements of a material's microstructure provides a nondestructive inspection tool with capabilities that are as good or better than most destructive measurement technologies.

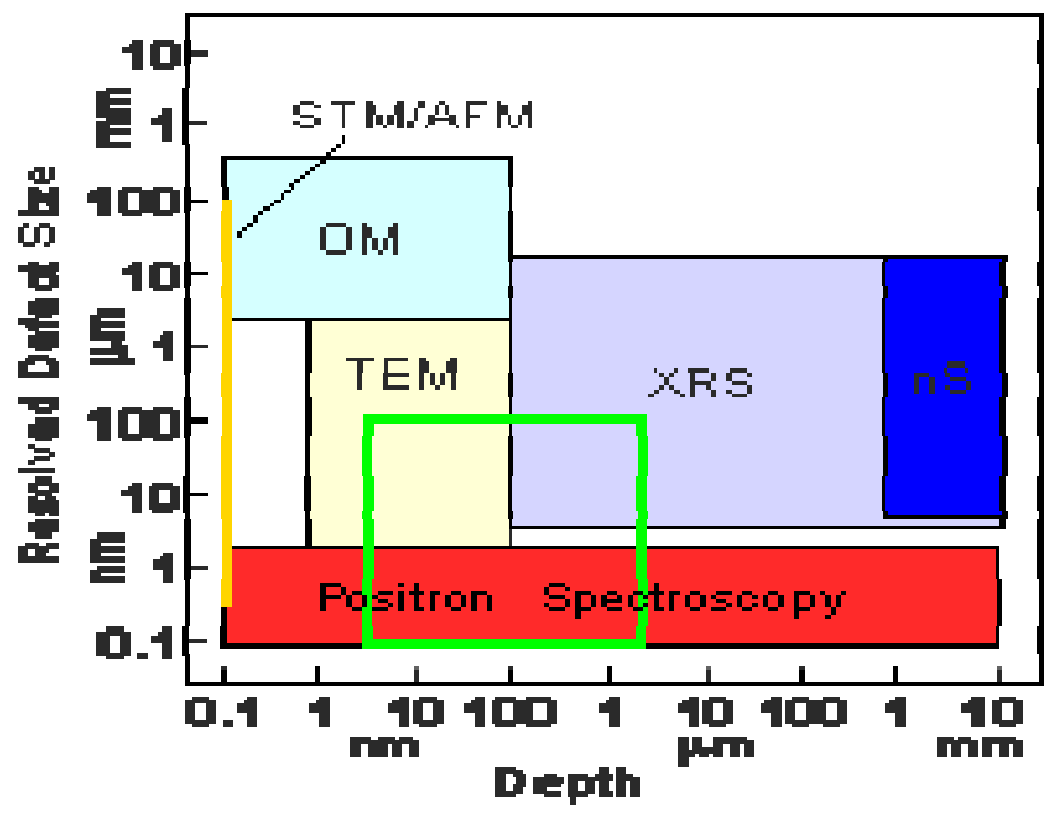

Figure 1. Resolved defect sizes for positron spectroscopy relative to other technologies. Shown are regions accessible to various standard techniques: optical microscopy $(\mathrm{OM})$, neutron scattering $(\mathrm{nS})$, transmission electron microscopy (TEM), scanning tunneling microscopy (STM), atomic force microscopy (AFM), and x-ray scattering (XRS). The solid green line outlines the range of interest for studies of fine lines used as electronic interconnects on semiconductor chips courtesy of Lawerence Livermore National Laboratory.

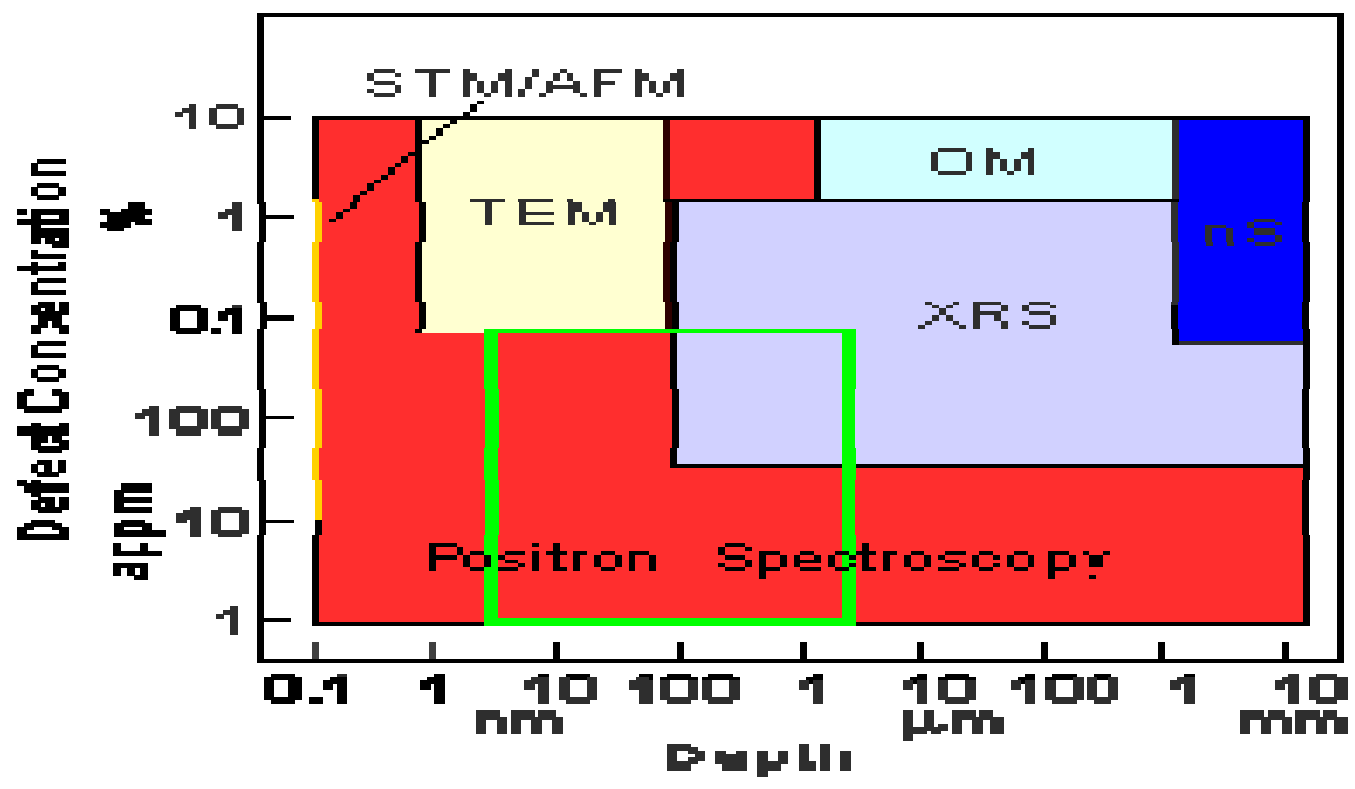

Figure 2. Measurable defect concentrations for positron spectroscopy relative to other technologies. 
The following sections present the measurement test plan for the CZT crystals along with a description of the measurement processes used for the crystals and the results of the measurements performed.

\section{CZT TEST PLAN}

CZT crystals were obtained from a number of sources including Fisk University, which has an ongoing CZT characterization program along with EV Products, a CZT manufacturer and Idaho State University where the crystals examined were part of a prior test program performed at Washington State University. Table 1 lists each of the crystals along with the dimensions and characteristics of each crystal examined as provided by the vendor.

Figure 3A shows the larger 1 inch long section of crystal (not detector grade) from Fisk University and Figure 3B shows an expanded view of the same crystal. Figure 4A shows a detector grade crystal from Fisk along with a DSPA source located on the surface of the crystal along with an expanded view Figure 4B. The copper DSPA probe dimensions used for the measurements were $0.64 \mathrm{~cm} \times 0.64 \mathrm{~cm}$. The volumetric PIPA measurements were performed using a $1.27 \mathrm{~cm}$ diameter collimator at both the accelerator and at the detector system. Consequently, for the boule section, the volume measured was $0.6 \mathrm{~cm}^{3}$ whereas the volumes measured for the individual detector specimens ranged from $0.25 \mathrm{~cm}^{3}$ for the EV products specimens to $0.4 \mathrm{~cm}^{3}$ for the CZT3 crystal.

The objective of the test plan was to assess the near surface and volumetric IPA methods ability to detect gradients in the composition of the long boule section and to detect differences between the "better" and "poorer" grades of CZT crystals as indicated by their ability to function as photon detectors.

Table 1. CZT crystal dimensions and detector characteristics.

\begin{tabular}{|l|l|c|l|l|}
\hline \multicolumn{1}{|c|}{$\begin{array}{c}\text { Crystal } \\
\text { Identification }\end{array}$} & \multicolumn{1}{c|}{$\begin{array}{c}\text { Crystal Dimensions } \\
(\mathrm{cm})\end{array}$} & $\begin{array}{c}\text { Detector } \\
\text { Grade }\end{array}$ & $\begin{array}{c}\text { Electron } \\
\text { Transport }\end{array}$ & Hole Transport \\
\hline Fisk Boule & $2.54 \mathrm{~L} \times 0.7 \times 0.7$ & No & & \\
\hline Fisk CZT3 & $0.92 \times 0.82 \times 0.3 \mathrm{~cm}$ thick & Yes & & \\
\hline HK-03-ISU & $1 \times 1 \times 0.21 \mathrm{~cm}$ thick & & & Good \\
\hline N4-Tip-001-ISU & $1 \times 1 \times 0.23 \mathrm{~cm}$ thick & & & Poor \\
\hline EV-3 & $1 \times 1 \times 0.20 \mathrm{~cm}$ thick & & Average & Average \\
\hline EV-13 & $1 \times 1 \times 0.20 \mathrm{~cm}$ thick & & Average & Good \\
\hline EV-21 & $1 \times 1 \times 0.20 \mathrm{~cm}$ thick & & Excellent & \\
\hline EV-27 & $1 \times 1 \times 0.20 \mathrm{~cm}$ thick & & Poor & \\
\hline
\end{tabular}

\section{CZT CRYSTAL MEASUREMENT RESULTS}

Induced Positron Annihilation (IPA) measurements were performed to assess the feasibility of using these techniques for discriminating between grades of crystals. The following sections discuss the results for each group of crystals. 


\subsection{Fisk University CZT Crystals}

Two crystals were obtained from Fisk University, of which one (CZT-3) was detector grade and the other was not. The detailed measurement results for these crystals are listed in Appendix B Tables B-1 and B-2 for the DSPA near surface and volumetric PIPA measurement results, respectively. Table 2 summarizes the S parameter near surface DSPA measurement results for the two Fisk crystals and Figure 5 shows the measurement results for both crystals. For the large $2.5-\mathrm{cm}$ long boule section, four individual $0.64 \mathrm{~cm} \times 0.64 \mathrm{~cm}$ measurements were performed along two opposite faces of the crystal to assess the potential for gradients in the microstructure of the crystal along the length of the section. As indicated in Table 2 and shown in Figure 5, the results indicate good reproducibility for Side 1 with an average uncertainty at 1 Standard Deviation of $+/-0.0002$ or less than $0.1 \%$ with the exception of the Side $1 \mathrm{~B}$ location, which produced a result considerably below those measured at the other locations. Additional measurements were performed which indicated that the $1 \mathrm{~B}$ result was a statistical outlier and that there is little difference in the $\mathrm{S}$ parameter results along the length of the Fisk boule specimen on Side 1. The S parameter results for both surfaces of this crystal suggest possible minor variations in the microstructure of the bulk section that are statistically significant. However, the differences are sufficiently small such that there is no obvious gradient in the microstructure on Side 1 of the Fisk crystal.

Side 2 of the Fisk boule section indicated more variability in the DSPA S parameter response than Side 1 and indicated differences relative to the Side 1 measurements. As shown in Table 1, although the average response for the entire face of Side 2 produced an average S parameter response $(0.5517 \pm$ $0.0006)$ to that of Side $1(0.5520 \pm 0.0006)$, the results are more variable and suggest some possible differences in microstructure near the end of the boule section. Arnold Burger at Fisk University plans to perform additional destructive measurements to better assess the characteristics of this section of crystal. These results will be compared with the IPA results.

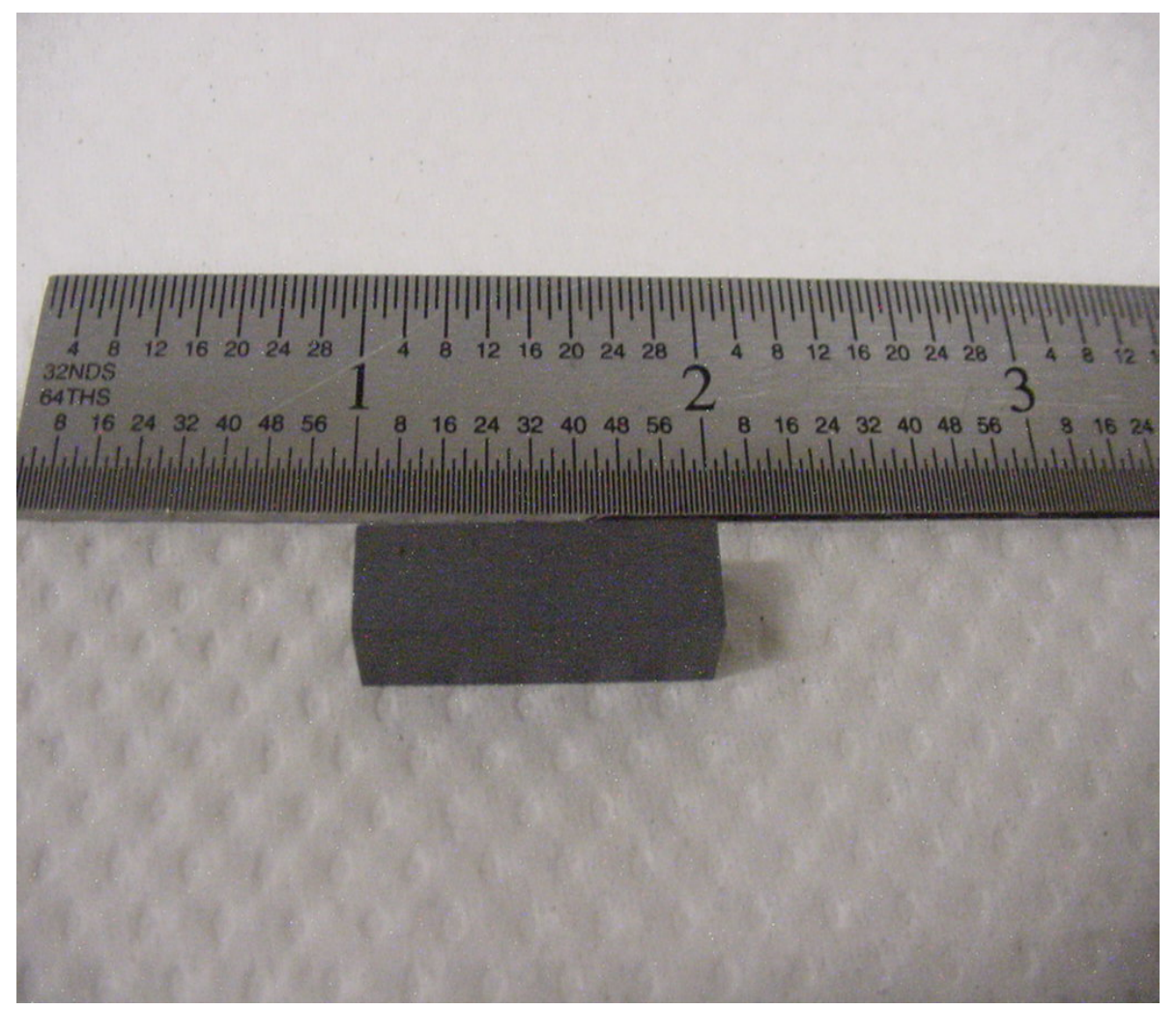

Figure 3A. Fisk University boule section (not detector grade). 


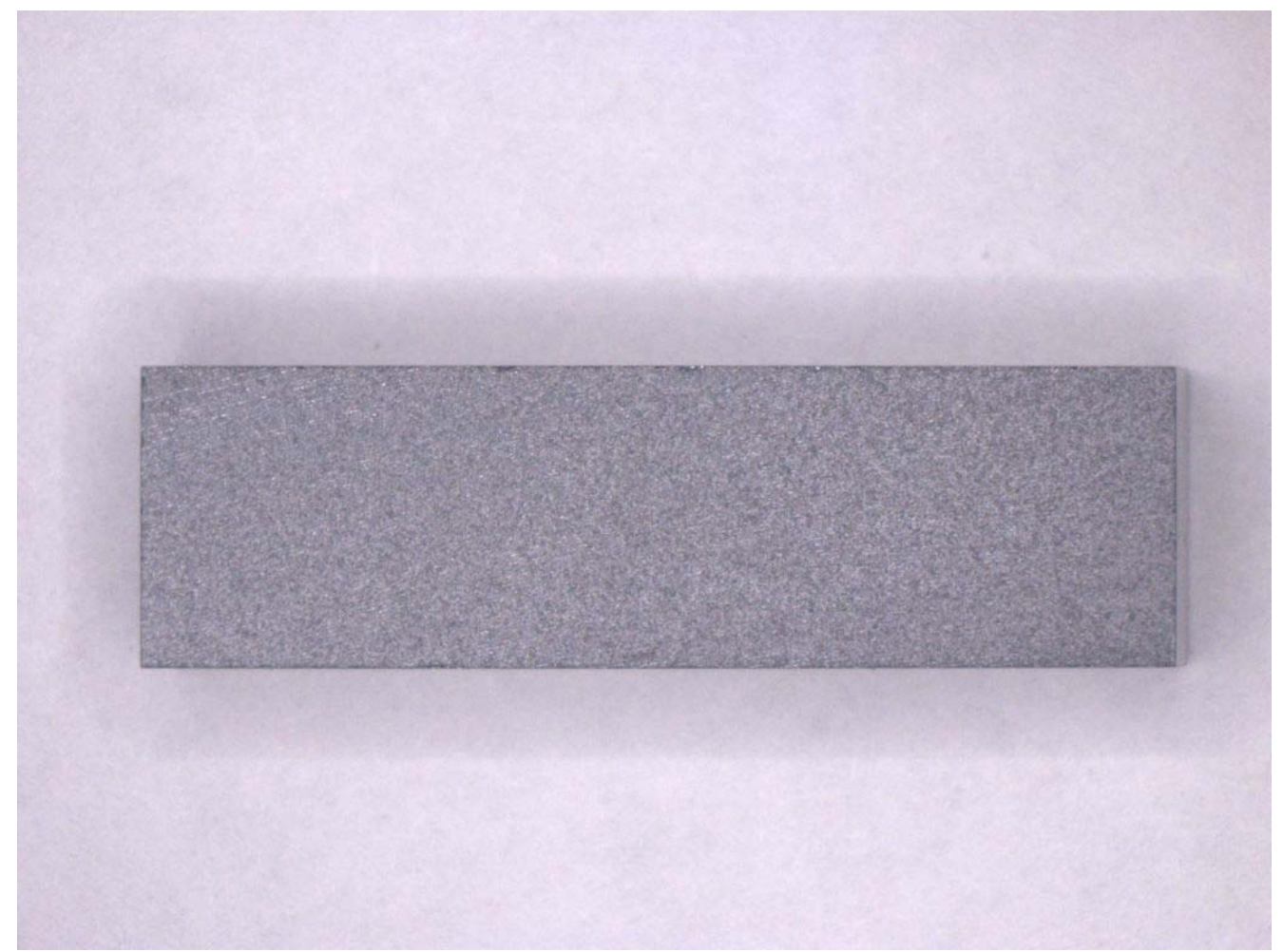

Figure 3B. Fisk University boule section - expanded view (not detector grade).

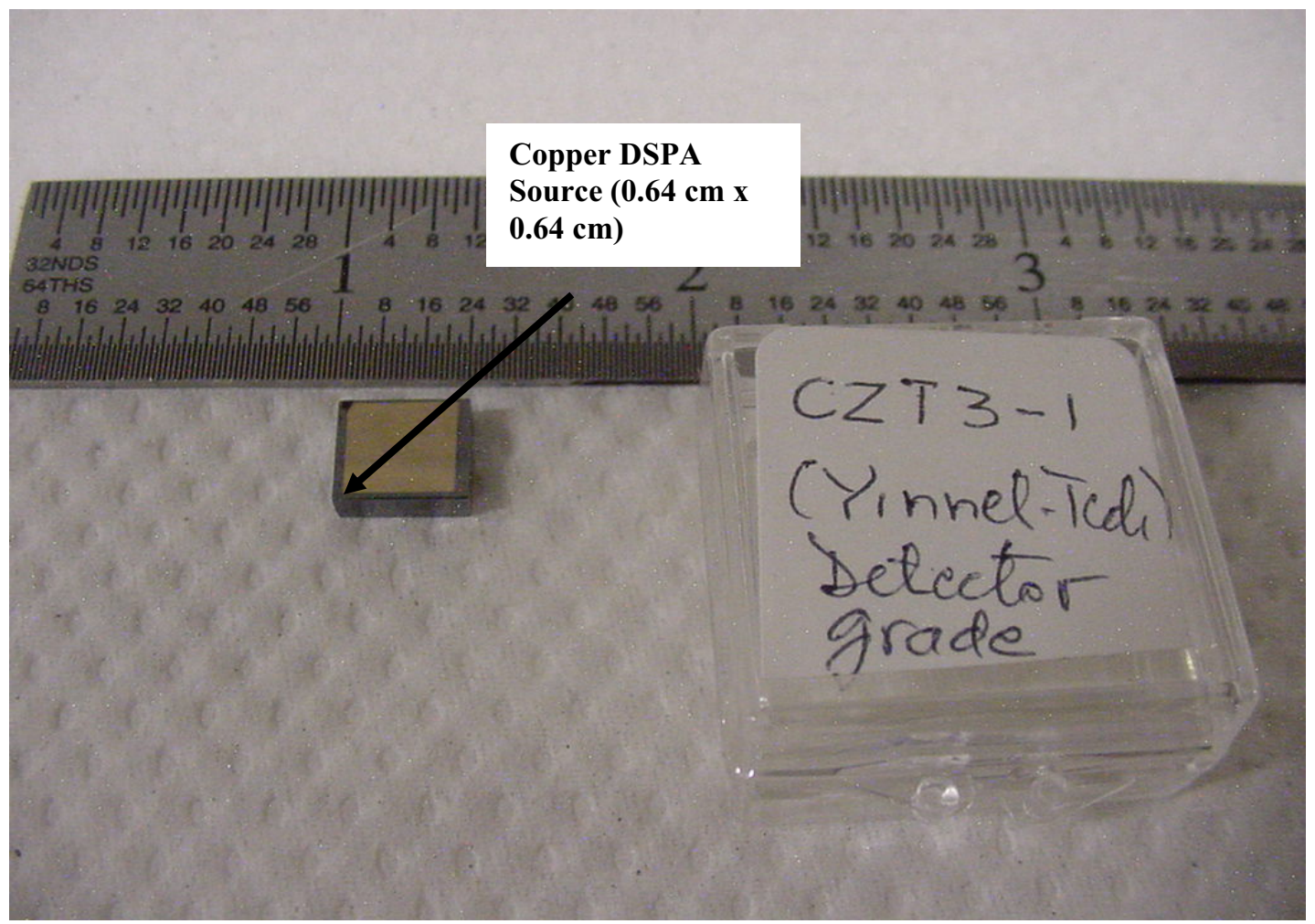

Figure 4A. Fisk University CZT 3-1 (detector grade). 
Figure 4B. Fisk University CZT 3-1 (Detector Grade) - Expanded View.

Table 2. Fisk CZT crystal near surface DSPA analysis.

\begin{tabular}{|c|c|c|c|}
\hline Side 1 & S Parameter \#1 & S Parameter \#2 & Average S Parameter \\
\hline A & 0.5520 & 0.5517 & $0.5518^{\text {a }}$ \\
\hline B & $0.5503^{\text {-b }}$ & & $0.5521^{\text {a }}$ \\
\hline C & 0.5522 & 0.5520 & \\
\hline D & 0.5519 & & 0.0002 \\
\hline Average/S.D. & 0.5520 & & $0.5515^{\text {a }}$ \\
\hline Side 2 & 0.5525 & & \\
\hline A & 0.5514 & 0.5517 & \\
\hline B & $0.5502^{\text {a }}$ & & \\
\hline C & 0.5511 & & \\
\hline D & 0.5517 & Side 2 & \\
\hline Average/S.D. & Side 1 & 0.5549 & \\
\hline \multicolumn{2}{|c|}{0.5548} & & \\
\hline CZT-3 & a different detector used for these measurements. \\
\hline \\
b. Outlier excluded from average measurement response.
\end{tabular}




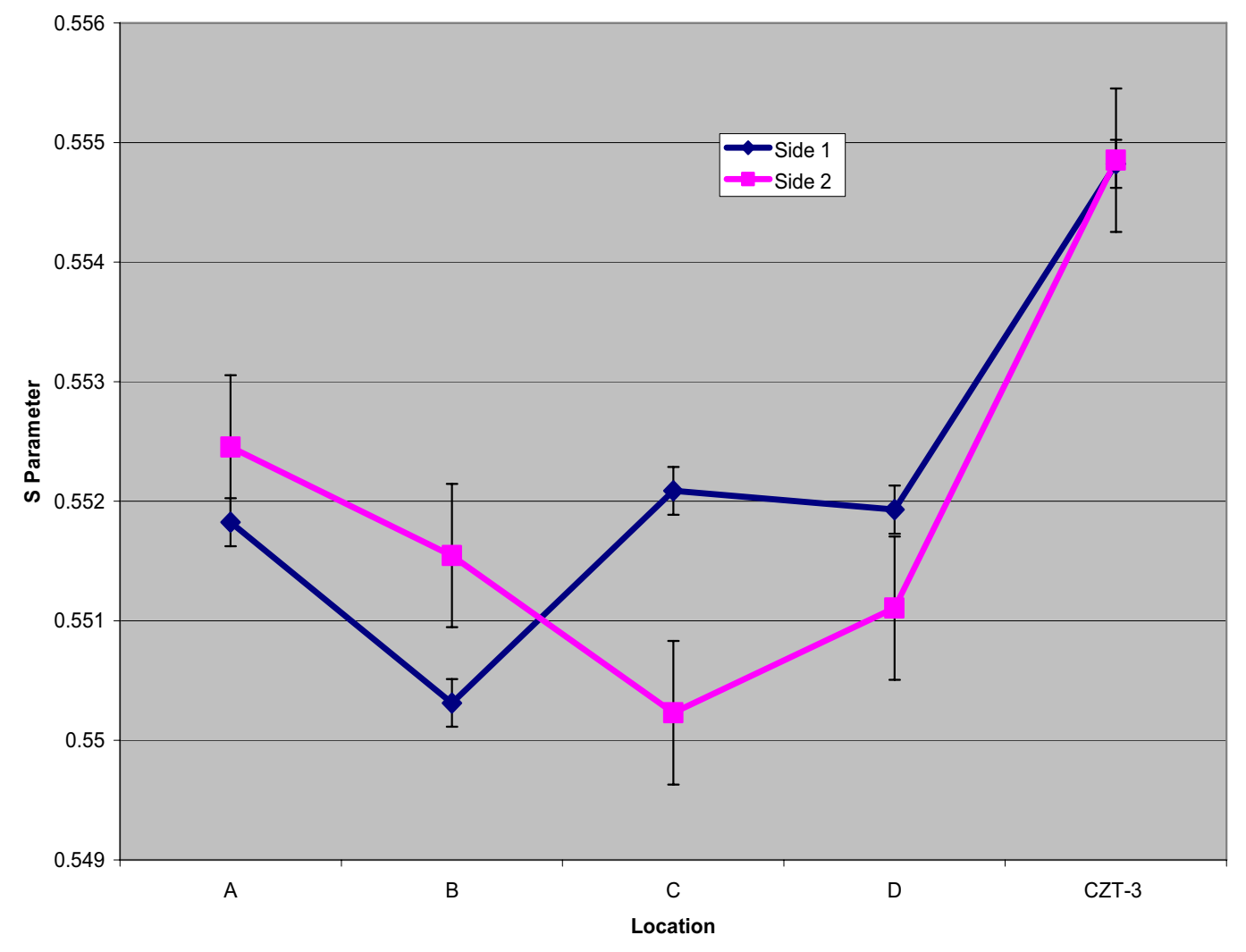

Figure 5. Fisk University CZT crystal DSPA results.

Table 2 lists the DSPA S parameter measurement results for the Fisk University CZT-3 crystal, which is considered a "detector grade" crystal. As shown in Figure 5, this crystal produced a considerably higher (0.0028), and similar S parameter response on both faces of the crystal. This crystal is a known detector grade crystal with good microstructural and compositional characteristics. The DSPA process is expected to penetrate any thin surface layer effect that may be present on the crystal due to the attachment of contacts on one surface of the crystal. The fact that both surfaces produce similar results suggests that there is no affect from the attachment of contacts on the surface of one face of the crystal.

The DSPA source used for the CZT measurements produces positrons that penetrate through most of the cross section of the CZT crystal as a significant percentage of the $2.9 \mathrm{MeV}$ positrons produced in the $0.025 \mathrm{~mm}$ thick crystal would be expected to penetrate well into the surface of the crystal before annihilating with electrons in the CZT crystal. The data from the boule section and the CZT-3 good crystal suggests that a higher S parameter response correlates with the detector grade CZT-3 crystal microstructure.

Table 3 lists the volumetric PIPA volumetric measurement results for the two Fisk CZT crystals and two ISU crystals measured. The Fisk crystals produced similar volumetric measurement results for both the boule section and the detector grade CZT-3 crystal, which suggests no significant measurable differences in the bulk microstructure of the detector grade and poor quality crystals. The similarity of the PIPA volumetric measurement results suggests that the volumetric measurement process is not as sensitive as the DSPA process to the characteristic microstructure of the Fisk crystals that results in poor detector grade characteristics. However, as will be discussed, the sensitivity of the volumetric PIPA technique appears higher for the EV products samples 
Measurements performed on two ISU CZT crystals, as listed in Table 3, were performed with the contacts attached, which likely affected the measurement results as activation of the contacts will affect the numerical $\mathrm{S}$ parameter response and contribute to the overall $\mathrm{S}$ parameter response measured. However, the results in Table 2 indicate a difference between the two crystals, which based on the EV Products data, to be discussed, suggests that the HK-O3 crystal is a higher grade detector crystal.

Table 3. Fisk CZT crystal volumetric PIPA measurement results.

\begin{tabular}{|c|c|c|c|c|}
\hline Sample/Measurement Location & S parameter \#1 & $\begin{array}{c}\text { S Parameter } \\
\# 2\end{array}$ & $\begin{array}{c}\text { Average S } \\
\text { Parameter }\end{array}$ & $\begin{array}{c}\text { Standard } \\
\text { Deviation }\end{array}$ \\
\hline Fisk Boule-End1 & 0.5568 & & 0.5568 & 0.0001 \\
\hline Fisk Boule-End2 & 0.5567 & & & \\
\hline CZT-3 & & & & \\
\hline & 0.5568 & 0.5572 & 0.5570 & 0.0003 \\
\hline HK-03 & & & & \\
\hline N4-TIP-001 & 0.5528 & & & \\
\hline
\end{tabular}

\subsection{EV Products Crystals}

A series of 4 CZT crystals were obtained from EV Products. These crystals have known electron and hole transport characteristics, which are used to define the quality of the crystal and it's ability to function as a radiation detector. Of the four crystals, No. 21 had the best characteristics and No. 27 likely the worst as listed in Table 1. Table 4 lists the results for the DSPA near surface measurements performed on the EV products samples. Two series of DSPA measurements were performed with different measurement parameters to attempt to optimize the measurement results. As listed in Table 4, the DSPA measurements were largely reproducible (standard deviation $+/-0.0005$ ) with the exception of Crystal 21 , which produced a wider range of responses during both series of measurements. Although there were some variations that were not statistically significant, the results clearly indicated that Crystal 21 produced the highest average $\mathrm{S}$ parameter response on either face of the crystal as compared to the other lower grade crystal. This is consistent with the results of the Fisk measurements where the highest $S$ parameter response correlated with the best quality crystal

Table 5 lists the volumetric PIPA measurement results for the four EV Products crystals measured and Figure 6 shows the average S Parameter results. These results are again consistent with the DSPA results for the Fisk crystals where the highest quality detector produced the highest $\mathrm{S}$ parameter response. In this case, Crystal 21 again produced the highest $S$ parameter response similar to the DSPA results and Crystal 03 the lowest. Based on the information provided by EV Products, Crystal 21 had excellent electron and average hole transport characteristics, whereas the other crystals had poorer characteristics.

These results generally indicate the ability of both the PIPA and DSPA processes to detect differences in the microstructure of the EV Products crystals and suggest that crystal quality may be assessed using this technique. Further measurements need to be performed to confirm the sensitivity of the two processes to the desired detector characteristics and to determine if it is possible to separate or discriminate the individual effects of hole and electron transport. 
In summary, the feasibility measurements performed on the Fisk University and EV Products crystals clearly suggest that detector grade crystals can be identified using the DSPA and PIPA processes (except for the PIPA measurements on the Fisk boule section) and that the two IPA techniques are sensitive to different microstructures with a sensitivity to surface effects more apparent for the Fisk samples and both surface and volumetric differences for the EV products samples. Further measurements are needed to verify the capability of the IPA techniques to the type and distribution of microstructural differences in the samples and the results needed to be compared with measurements from destructive measurement methods to validate the NDI measurements performed.

Table 4. EV products CZT crystal DSPA measurement results.

\begin{tabular}{|c|c|c|c|c|c|c|}
\hline Specimen ID & Side 1 & & Side 2 & & & \\
\hline Series 1 & $\begin{array}{c}\text { S Parameter } \\
\# 1\end{array}$ & $\begin{array}{c}\text { S Parameter } \\
\# 2\end{array}$ & $\begin{array}{c}\text { S Parameter } \\
\# 1\end{array}$ & $\begin{array}{c}\text { S Parameter } \\
\# 2\end{array}$ & $\begin{array}{c}\text { Average S } \\
\text { Parameter }\end{array}$ & $\begin{array}{c}\text { Standard } \\
\text { Deviation }\end{array}$ \\
\hline Crystal 03 & 0.5479 & 0.5488 & 0.5479 & & 0.5482 & 0.0005 \\
\hline Crystal 13 & 0.5484 & & 0.5491 & & 0.5488 & 0.0005 \\
\hline Crystal 21 & 0.5490 & & 0.5513 & & 0.5502 & 0.0016 \\
\hline Crystal 27 & 0.5485 & & 0.5493 & 0.5480 & 0.5487 & 0.0005 \\
\hline & & & & & & \\
\hline Series 2 & & & & & & \\
\hline & Side 1 & & 0.5493 & & 0.5490 & 0.0004 \\
\hline Crystal 03 & 0.5488 & & 0.5511 & & 0.5502 & 0.0013 \\
\hline Crystal 21 & 0.5493 & & 0.5492 & & 0.5488 & 0.0005 \\
\hline Crystal 27 & 0.5484 & & & & & \\
\hline
\end{tabular}

Table 5. EV products CZT crystal PIPA measurement results.

\begin{tabular}{|l|c|c|c|c|}
\hline Specimen ID & S Parameter \#1 & S Parameter \#2 & $\begin{array}{c}\text { Average S } \\
\text { Parameter }\end{array}$ & $\begin{array}{c}\text { Standard } \\
\text { Deviation }\end{array}$ \\
\hline Crystal 3 & 0.5522 & 0.5526 & 0.5524 & 0.0002 \\
\hline Crystal 13 & 0.5515 & 0.5528 & 0.5521 & 0.0009 \\
\hline Crystal 21 & 0.5537 & 0.5534 & 0.5535 & 0.0002 \\
\hline Crystal 27 & 0.5506 & 0.5515 & 0.5511 & 0.0006 \\
\hline
\end{tabular}




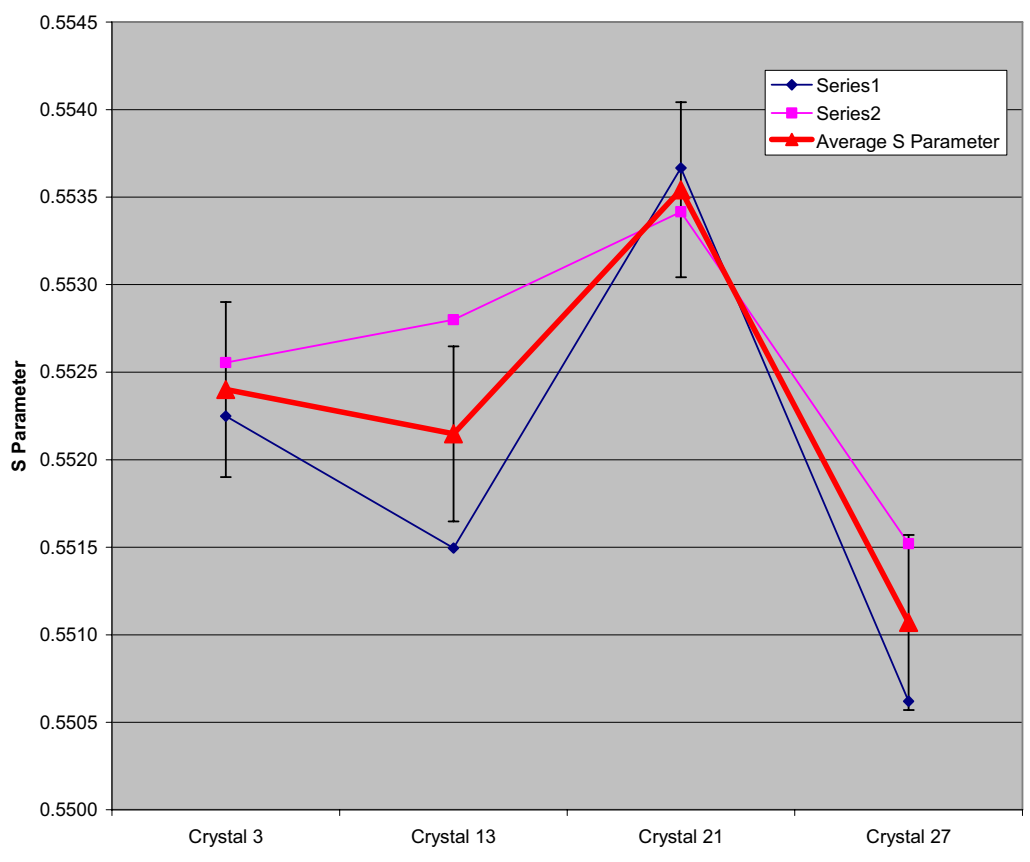

Figure 6. EV products CZT crystal PIPA measurement results. 


\section{Appendix A}

\section{Positron Measurement Analysis Methodology}




\section{Appendix A}

\section{Positron Measurement Analysis Methodology}

A positron, a form of antimatter, is a charged particle equal in mass to an electron with a positive charge equal in magnitude to the negative charge of the electron. Traditionally, when injected into a metal, positrons rapidly lose most of their kinetic energy by collisions with ions and free electrons. Many of these collisions occur on the surface or surface coating of the material and may not reflect the characteristics of the bulk material. An energetic positron injected into a solid is slowed down to thermal energies within about $10 \mathrm{ps}\left(1 \mathrm{ps}=10^{-12} \mathrm{~s}\right)$. Upon thermalization, the injected positron diffuses away from the point where it thermalized, until it finally annihilates with an electron. During this diffusion process, the positrons are repelled by positively charged nuclei and thus seek defects such as dislocations in the lattice sites, where the concentration of nuclei is lower. A thermalized positron has a typical mean velocity of $10^{-5} \mathrm{~m} / \mathrm{s}$ (Hughes, 1980). The balance between the diffusion rate (after thermalization) and the annihilation rate of thermalized positrons is such that on average each positron has time to diffuse just a few tens of a micrometer from its point of thermalization. Typical mean lifetime of a thermalized positron before it annihilates with an electron is about 200 ps (Hughes, 1980). The distance traveled after thermalization encompasses about $10^{5}$ lattice sites, so there is a good chance that the positron will encounter a defect and be trapped, even if the defects are present at quite a small concentration (10 parts per million of defects ensures that on average there is one defect for every $10^{5}$ lattice sites) (Hughes, 1980).

Complete annihilation of both particles occurs when a positron encounters an electron and their mass is converted into pure energy in the form of two, or occasionally three, gamma rays. If the positron and the electron with which it annihilates were both at rest at the time of decay, the two gamma rays would be emitted in exactly opposite directions (180 degrees apart), in accordance with the principle of conservation of momentum. And, each annihilation gamma ray would have an energy of $0.511 \mathrm{MeV}$, the rest energy of an electron and of a positron (Hautojarvi, 1979; Allen et al., 1988). In fact, however, nearly all the positrons are essentially at rest, but the electrons are not.

The momentum of the electrons determines the momentum of the annihilating pairs and causes the direction of the gamma rays to deviate from the nominal value of 180 degrees. Likewise, the energy of the annihilation gamma rays deviates slightly from $0.511 \mathrm{MeV}$, depending on the momentum of the electrons, because of the Doppler effect. Three key characteristics of positrons and the radiation that they emit upon annihilation with electrons make the positron annihilation method useful for detecting the presence and size of microscopic flaws in metals.

- $\quad$ First, their positive electrical charge causes them to be repelled by protons. This characteristic accounts for their attraction to dislocations, vacant lattice sites, vacancy clusters, cavities, and other open volumes (voids) in the metal, where the density of atomic nuclei is lower. Thus, a small increase in the number or size of the microscopic defects in a sample results in a large increase in the proportion of annihilation events occurring in the defects.

- Second, the annihilation radiation is sensitive to the momentum distribution of the electrons with which positrons annihilate. Defects contain a higher ratio of free electrons to core electrons than perfect metal. This phenomenon can be explained by the tendency of free (conduction) electrons to spill over into the defect more than core electrons. Core electrons have a much higher linear momentum than do free electrons. Thus, gamma rays from annihilation events involving free electrons are more likely to approximate the energy $(0.511 \mathrm{MeV})$ and direction (180 degrees) typical of gamma rays produced by events involving positrons and electrons at rest. These 
characteristics make it possible to detect the presence of defects from the energy spectrum of the gamma ray emissions and from the spectrum of angles of deviation from 180 degrees.

- Third, because the density of electrons is lower in defects than in perfect material, the mean lifetime of thermalized positrons trapped in defects is longer than those diffusing in perfect material. Within a few picoseconds after the positron is injected into the material, the nucleus (in the source) emits an energetic $1.28 \mathrm{-MeV}$ gamma ray (in the case of a "Na" source) that serves as a birth signal, (Hautojarvi, 1979). The lifetime of the positron can be measured as the time elapsed between the birth and annihilation gamma rays. Thus, measurement of positron lifetimes can also be used to indicate the presence of defects in the material.

Measurement of the gamma ray angles (angular correlation), energy spectrum (Doppler broadened line-shape), and positron lifetime will determine whether the positrons are interacting with free electrons at defects or core electrons in the bulk material. Those measurements are illustrated in Figure A-1 (Schultz and Snead, 1990). Figure A-1(a) illustrates measurement of the distribution of angles between two annihilation gamma rays about the nominal value of 180 degrees. This deviation from collinearity between two $0.511 \mathrm{MeV}$ annihilation gamma rays is a product of the momentum of the annihilating electron. Less deviation from collinearity indicates the presence of defects. The electron momentum also produces a Doppler shift in the $0.511 \mathrm{MeV}$ gamma annihilation radiation, and this shift can be seen in an accurate energy measurement of one of the two gamma rays emitted by an individual annihilation, as illustrated in Figure A-1(b). With a Doppler broadened line-shape measurement, the distribution of the annihilation gamma ray energies about the nominal energy of $0.511 \mathrm{MeV}$ is measured. Less deviation from the nominal $0.511 \mathrm{MeV}$ energy value (more gamma rays detected) in a given period of time or very near $0.511 \mathrm{MeV}$ and fewer detected at other energy levels indicates the presence of defects. With a positron lifetime measurement, Figure A-1(c), the distribution of time between a fiducial gamma ray emitted from the source when the positron is ejected and the annihilation gamma rays observed is measured and provides information not only on the quantity of defects, but due to variations in the lifetime, on the type of defects present.

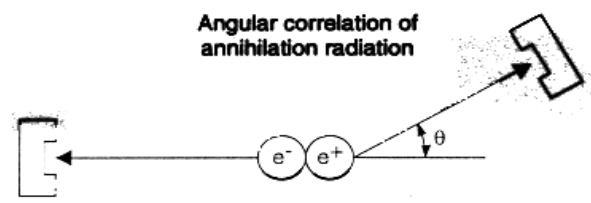

(a)

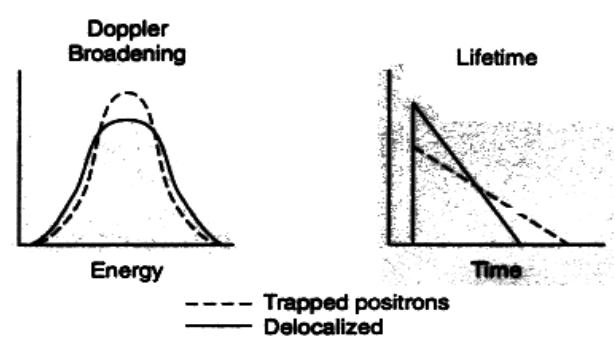

Figure A-1. The three most common experimental positron techniques for measuring electron momentum are (a) angular correlation of annihilation radiation, (b) doppler broadening, and (c) positron lifetime. When positrons get trapped in defects, there is a reduced overlap with energetic core electrons, leading to less angular deviation (a), more counts at or near the $0.511 \mathrm{MeV}$ peak (b), and longer positron lifetimes (c). 
The PIPA process generates positrons deep within the bulk material through the application of high-energy x-ray bombardment of the target material. Positrons are formed when the x-rays cause a neutron to be ejected from a material's atom (photo-neutron reaction) and the resultant atomic isotope decays into a more stable material. Positrons are effectively positively charged electrons.

In the case of a material that is "as manufactured" or with limited defects present, the positron response is dictated by interactions with core and valence electrons in the material that provide an $\mathrm{S}$ parameter response that is representative of the microstructure of the material. This measurement response is considered to be representative of the material. Deviations induced by changes in the microstructure such as increased dislocation densities induced by fatigue or other effects are indicated by changes in the measurement response relative to the standard response from the known material.

Positrons migrate to locations where the positive charge potential is least. Due to the inherently positive charge of the protons in the atom, the less positive potential areas in the lattice structure are found in dislocations, voids, and atomic defect areas where the distance between the protons is greatest. Figure A-2 illustrates the basic operating model and functional procedure of Photon Induced Positron Annihilation.

When a positron enters a void, it quickly loses momentum. It remains at rest in the void until it interacts with an electron, which may be present on the surface of the void, or as a conduction electron. Localized positrons trapped in bounded states in a variety of dislocation-like or chemically-induced defects can be identified and their concentration recorded. This information read, analyzed and presented on the PIPA instrumentation provides data for determination of location and concentration of surface and subsurface anomalies.

When the electron-positron pair annihilate in the defect region, there is little or no momentum associated with the reaction, and consequently, two $511 \mathrm{keV}$ gamma ray photons are produced with little associated Doppler broadening. These gamma photons are detected and provide the PIPA equipment with base line data for analysis. Figure A-3 shows one of the methods used to measure Doppler broadening in this gamma-ray peak.

Although several analytical techniques may be used for positron annihilation analysis, the primary measurement techniques to be used in this project are Doppler broadening and positron lifetime measurements. These methods can provide information not only on the defect concentrations and size, but on the types of defects as well.

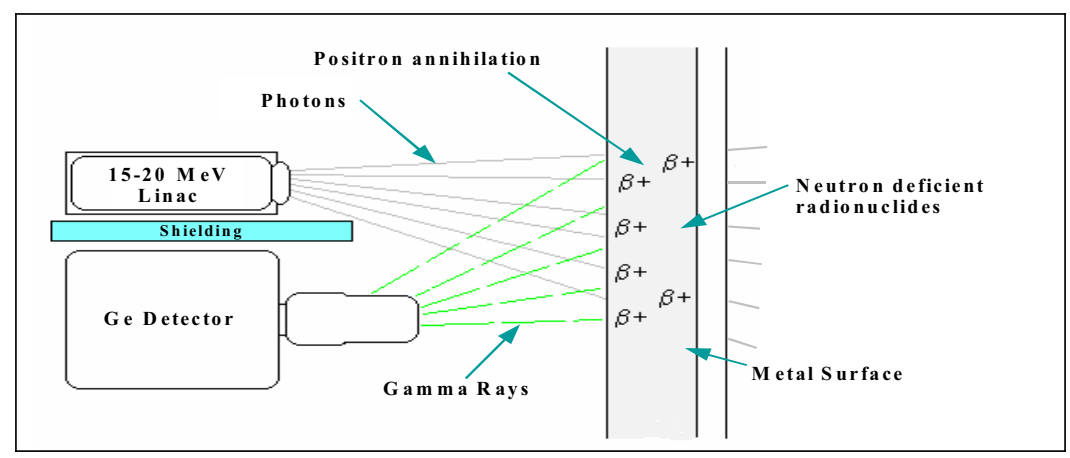

Figure A-2. Photon induced positron annihilation. 


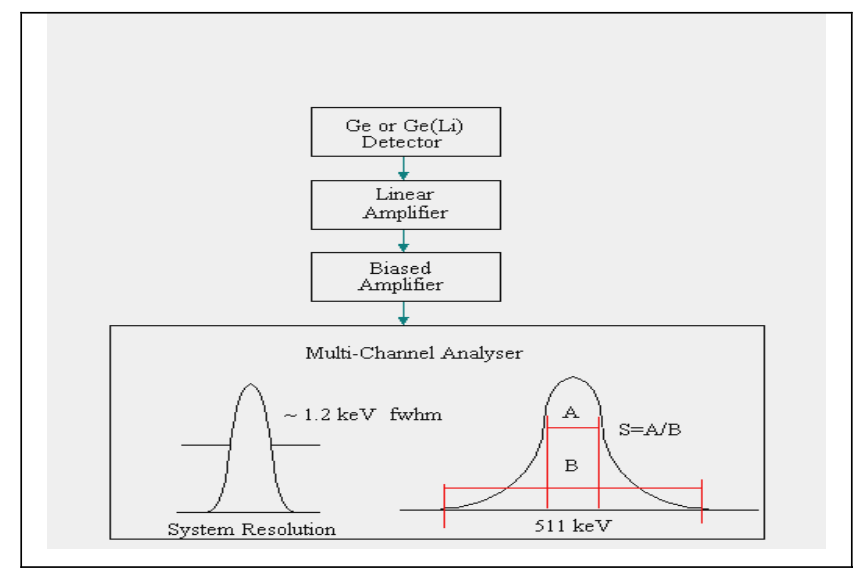

Figure A-3. Doppler broadening analysis for the S parameter.

Doppler broadening effectively compares the relationship of the positron annihilation gammas received in the narrow, channelized region surrounding the $511 \mathrm{keV}$ energy level, primarily representing annihilations occurring in the defected areas, against all annihilation energy levels that occur. This "line shaping parameter" or " $\mathrm{S}$ " factor for the material is compared to known " $\mathrm{S}$ " parameters for similar "as manufactured" and failed materials to quantitatively determine a defect density and lattice structure damage level percentage. The positron lifetime analysis utilizes two different type gamma ray detectors and compares output readings with known database information to produce defect type, size, and density information; in addition to the information provided by the Doppler broadening method.

PIPA techniques have shown remarkable identification and measurement capabilities that include:

- Identify atomic lattice defects $<10$ microns in size.

- $\quad$ Measurement uncertainties on the order of less than $1 \%$.

- Defect detection at depths up to 3.5 inches for titanium and aluminum; 2 inches for steel.

- $\quad$ Multi-layer defect detection in composites.

- $\quad$ Depending on ease of access, measurements can be taken from both sides. (Doubling the depth-detection capability).

- $\quad$ Cross-sectional analysis.

- $\quad$ Assess lattice damage at less than $1 \%$ fatigue. Crack $=100 \%$.

Positron annihilation has been used for decades to study fatigue and defect characteristics in materials. Figures A-4 and A-5 provide a comparison of positron beam spectroscopy to laboratory NDT technologies with reference to defect size resolution and defect concentration. PIPA provides defect detection at levels at or below those found in a laboratory environment, with a technology capable for 


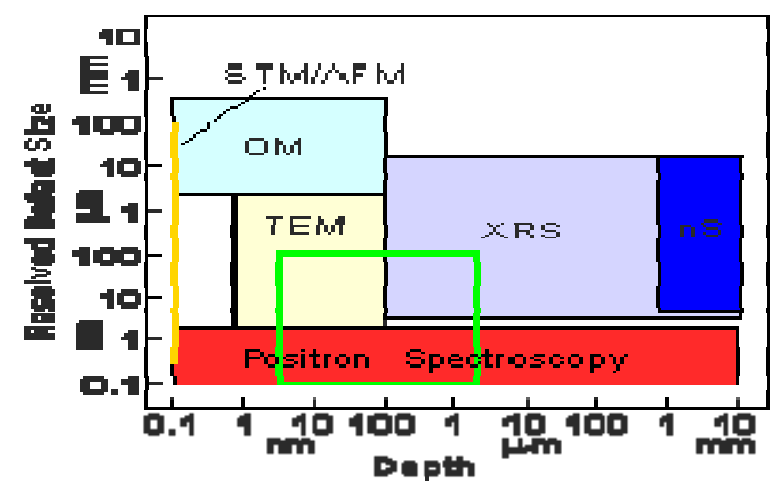

Figure A-4. Defect resolution methods.

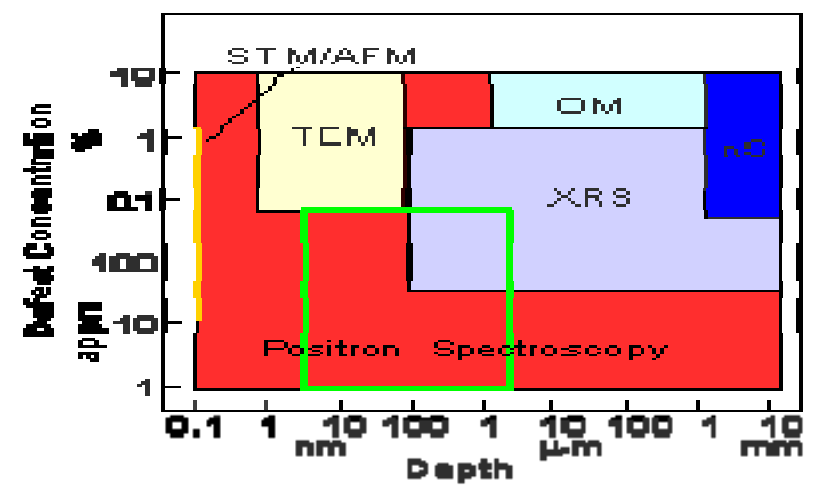

Figure A-5. Defect concentration methods.

Figures A-4 and A-5 Resolved Defect Size and Concentration Legend: Shown are regions accessible to various standard techniques: optical microscopy $(\mathrm{OM})$, neutron scattering $(\mathrm{nS})$, transmission electron microscopy (TEM), scanning tunneling microscopy (STM), atomic force microscopy (AFM), and x-ray scattering (XRS). The solid green line outlines the range of interest for studies of fine lines used as electronic interconnects on semiconductor chips.

application in a maintenance environment. PIPA takes positron beam spectroscopy atomic level defect detection effectiveness much further by generating the positron reaction deep within the bulk material through the application of high energy x-rays to the material. (Figures provided by Lawrence Livermore National Laboratory).

Calculations have been performed to define the penetration depth of most positron energies into stainless steel from the surface (Helmer 1997). These calculations were performed to determine the fraction of the injected positrons that annihilated as a function of depth in the material. To determine the penetration of positrons in steel/iron, a National Bureau of Standards report on stopping powers and ranges of electrons and positrons (NBSIR 1982) was used to obtain the range of the positrons as a function of energy. The primary conclusion of this analysis is that about $84 \%$ of the positrons produced by Cobalt-58 annihilate within the first $0.1 \mathrm{~mm}$ and the remaining $16 \%$ annihilates within the second $0.1 \mathrm{~mm}$. Consequently, any type of surface coating or other machining would affect penetration and, thus, the positron response. In contrast, the PIPA technique is not affected by surface conditions nor component geometry, hence essentially all positrons annihilate in the area to be examined. 


\section{Appendix A REFERENCES}

1. ASTM 1972. "Standard Definitions of Terins Relating to Fatigue Testing and Statistical Analysis of Data," ASTM Designation E206-72.

2. Forsyth, P., J. E., 1969. "The Physical Basis of Metal Fatigue”, American Elsevier Publishing Co., New York.

3. Fuchs, H. O., and R. 1. Stephens, 1980, "Metal Fatigue in Engineering”, John Wiley and Sons, New York.

4. Gauster, W. B., et al. 1978. "A Study of Deformation Fatigue of 316 Stainless Steel at Room Temperature by Positron Annihilation”, NUREG CR/0118.

5. Hughes, A. E. 1980. "Probing Materials with Positrons," Materials Engineering, Vol. 2, September, pp. 34-40.

6. Lapides, M. E. et al. 1994. "Measuring Precrack Initiation Fatigue State in Reactor Pressure Vessel Steels”, PVP-Vol. 283, Plant Systems/Components Aging Management, ASME 1994. 


\section{Appendix B \\ Positron Systems}

\section{DSPA and PIPA CZT Measurement Results}




\section{Appendix B \\ Positron Systems}

\section{DSPA and PIPA CZT Measurement Results}

Table B-1. Fisk and Idaho State University CZT crystal DSPA measurement results.

\begin{tabular}{|c|c|c|c|c|c|c|c|}
\hline $\begin{array}{c}\text { Spectrum } \\
\text { ID }\end{array}$ & $\begin{array}{c}\text { Sample } \\
\text { Description }\end{array}$ & Location & Analysis & $\begin{array}{c}\mathrm{S} \\
\text { Parameter } \\
\end{array}$ & $\begin{array}{l}\text { S/W } \\
\text { Ratio }\end{array}$ & $\begin{array}{c}\text { W } \\
\text { Parameter }\end{array}$ & Comments \\
\hline $\begin{array}{l}\text { DP486- } \\
1117003\end{array}$ & $\begin{array}{l}\text { Fisk U CZT } \\
\text { Crystal }\end{array}$ & Side 1A & DSPA & 0.552 & 2.7366 & 0.2017 & \\
\hline $\begin{array}{l}\text { DP486- } \\
1117004\end{array}$ & $\begin{array}{l}\text { Fisk U CZT } \\
\text { Crystal }\end{array}$ & Side 1B & DSPA & 0.5503 & 2.6945 & 0.2042 & \\
\hline $\begin{array}{l}\text { DP486- } \\
1117005\end{array}$ & $\begin{array}{l}\text { Fisk U CZT } \\
\text { Crystal }\end{array}$ & Side 1C & DSPA & 0.5522 & 2.7242 & 0.2027 & \\
\hline $\begin{array}{l}\text { DP486- } \\
1117006\end{array}$ & $\begin{array}{l}\text { Fisk U CZT } \\
\text { Crystal }\end{array}$ & Side 1D & DSPA & 0.5519 & 2.7201 & 0.2029 & \\
\hline $\begin{array}{l}\text { DP486- } \\
1117007\end{array}$ & $\begin{array}{l}\text { Fisk U CZT } \\
\text { Crystal }\end{array}$ & Side $2 \mathrm{~A}$ & DSPA & 0.5525 & 2.7317 & 0.2022 & \\
\hline $\begin{array}{l}\text { DP486- } \\
1117008 \\
\end{array}$ & $\begin{array}{l}\text { Fisk U CZT } \\
\text { Crystal }\end{array}$ & Side 2B & DSPA & 0.5514 & 2.7112 & 0.2034 & \\
\hline $\begin{array}{l}\text { DP486- } \\
1117009\end{array}$ & $\begin{array}{l}\text { Fisk U CZT } \\
\text { Crystal }\end{array}$ & Side $2 \mathrm{C}$ & DSPA & 0.5502 & 2.7 & 0.2038 & \\
\hline $\begin{array}{l}\text { DP486- } \\
1117010\end{array}$ & $\begin{array}{l}\text { Fisk U CZT } \\
\text { Crystal }\end{array}$ & Side 2D & DSPA & 0.5511 & 2.7125 & 0.2032 & \\
\hline $\begin{array}{l}\text { DP486- } \\
1210003\end{array}$ & $\begin{array}{l}\text { Crystal } \\
\text { w/contacts }\end{array}$ & "Dot" side & DSPA & 0.5689 & 2.9538 & 0.1926 & 0.5548 \\
\hline $\begin{array}{l}\text { DP486- } \\
1210004\end{array}$ & $\begin{array}{l}\text { Crystal } \\
\text { w/contacts }\end{array}$ & $\begin{array}{l}\text { Unmarked } \\
\text { side }\end{array}$ & DSPA & 0.5689 & 2.9613 & 0.1921 & 0.5548 \\
\hline $\begin{array}{l}\text { DP486- } \\
1210005\end{array}$ & $\begin{array}{l}\text { Crystal } \\
\text { w/contacts }\end{array}$ & "Dot" side & DSPA & $-^{\mathrm{a}}$ & $-^{\mathrm{a}}$ & $-^{\mathrm{a}}$ & $-^{\mathrm{a}}$ \\
\hline $\begin{array}{l}\text { DP486- } \\
1210006 \\
\end{array}$ & $\begin{array}{l}\text { Original } \\
\text { crystal }\end{array}$ & Side 1A & DSPA & 0.5657 & 2.8946 & 0.1954 & 0.5517 \\
\hline $\begin{array}{l}\text { DP486- } \\
1210007 \\
\end{array}$ & $\begin{array}{l}\text { Original } \\
\text { crystal }\end{array}$ & Side $2 B$ & DSPA & 0.5657 & 2.8851 & 0.1961 & 0.5517 \\
\hline $\begin{array}{l}\text { DP486- } \\
1210008\end{array}$ & $\begin{array}{l}\text { Original } \\
\text { crystal }\end{array}$ & Side 1C & DSPA & 0.566 & 2.8955 & 0.1955 & 0.5517 \\
\hline
\end{tabular}


Table B-2. Fisk and Idaho State University CZT crystal PIPA measurement results.

\begin{tabular}{|l|l|l|l|l|l|l|l|}
\hline \multicolumn{1}{|c|}{$\begin{array}{c}\text { Spectrum } \\
\text { ID }\end{array}$} & $\begin{array}{c}\text { Sample } \\
\text { Description }\end{array}$ & Location & Analysis & $\begin{array}{c}\text { S } \\
\text { Parameter }\end{array}$ & $\begin{array}{c}\text { S/W } \\
\text { Ratio }\end{array}$ & $\begin{array}{c}\text { W } \\
\text { Parameter }\end{array}$ & Comments \\
\hline $\begin{array}{l}\text { DP486- } \\
0204005\end{array}$ & $\begin{array}{l}\text { Crystal } \\
\text { w/contacts }\end{array}$ & $\begin{array}{l}\text { Over whole } \\
\text { crystal }\end{array}$ & PIPA & 0.5568 & 2.8259 & 0.197 & \\
\hline $\begin{array}{l}\text { DP486- } \\
0207003\end{array}$ & $\begin{array}{l}\text { Crystal } \\
\text { w/contacts }\end{array}$ & $\begin{array}{l}\text { Over whole } \\
\text { crystal }\end{array}$ & PIPA & 0.5528 & 2.7414 & 0.2017 & $\begin{array}{l}\text { Hunt } \\
\text { Crystal }\end{array}$ \\
\hline $\begin{array}{l}\text { DP486- } \\
0207004\end{array}$ & $\begin{array}{l}\text { Crystal } \\
\text { w/contacts }\end{array}$ & $\begin{array}{l}\text { Over whole } \\
\text { crystal }\end{array}$ & PIPA & 0.5505 & 2.7059 & 0.2034 & $\begin{array}{l}\text { Hunt } \\
\text { Crystal }\end{array}$ \\
\hline $\begin{array}{l}\text { DP486- } \\
0207005\end{array}$ & $\begin{array}{l}\text { Crystal } \\
\text { w/contacts }\end{array}$ & $\begin{array}{l}\text { Over whole } \\
\text { crystal }\end{array}$ & PIPA & 0.5572 & 2.8235 & 0.1973 & $\begin{array}{l}\text { Fisk } \\
\text { Crystal }\end{array}$ \\
\hline $\begin{array}{l}\text { DP486- } \\
0504007\end{array}$ & $\begin{array}{l}\text { Fisk crystal } \\
\text { CZT3-1 }\end{array}$ & $\begin{array}{l}\text { Center of } \\
\text { crystal }\end{array}$ & PIPA & 0.5549 & 2.8029 & 0.19797 & \\
\hline $\begin{array}{l}\text { DP486- } \\
0505002\end{array}$ & $\begin{array}{l}\text { Fisk crystal } \\
- \text { original }\end{array}$ & End 1 & PIPA & 0.5560 & 2.8189 & 0.1972 & $\begin{array}{l}\text { At 2400 } \\
\text { Seconds }\end{array}$ \\
\hline $\begin{array}{l}\text { DP486- } \\
0505003\end{array}$ & $\begin{array}{l}\text { Fisk crystal } \\
- \text { original }\end{array}$ & End 1 & PIPA & 0.5568 & 2.8295 & 0.1968 & $\begin{array}{l}\text { At 500K } \\
\text { Counts }\end{array}$ \\
\hline $\begin{array}{l}\text { DP486- } \\
0505006\end{array}$ & $\begin{array}{l}\text { Fisk crystal } \\
- \text { original }\end{array}$ & End 2 & PIPA & 0.5568 & 2.8337 & 0.1965 & $\begin{array}{l}\text { At 2400 } \\
\text { Seconds }\end{array}$ \\
\hline $\begin{array}{l}\text { DP486- } \\
0505007\end{array}$ & $\begin{array}{l}\text { Fisk crystal } \\
- \text { original }\end{array}$ & End 2 & PIPA & 0.5567 & 2.8313 & 0.1966 & $\begin{array}{l}\text { At 500K } \\
\text { Counts }\end{array}$ \\
\hline
\end{tabular}


Table B-3. EV. Products CZT crystal DSPA measurement results.

\begin{tabular}{|c|c|c|c|c|c|c|c|}
\hline $\begin{array}{l}\text { Spectrum } \\
\text { ID }\end{array}$ & $\begin{array}{c}\text { Sample } \\
\text { Description }\end{array}$ & Location & Analysis & $\begin{array}{c}\mathrm{S} \\
\text { Parameter }\end{array}$ & $\begin{array}{l}\mathrm{S} / \mathrm{W} \\
\text { Ratio }\end{array}$ & $\begin{array}{c}\text { W } \\
\text { Parameter }\end{array}$ & Comments \\
\hline $\begin{array}{l}\text { DP486- } \\
0406003\end{array}$ & Crystal 03 & $\begin{array}{l}\text { Center of } \\
\text { crystal }\end{array}$ & DSPA & 0.5479 & 2.6506 & 0.2067 & Side 1 \\
\hline $\begin{array}{l}\text { DP486- } \\
0406004\end{array}$ & Crystal 13 & $\begin{array}{l}\text { Center of } \\
\text { crystal }\end{array}$ & DSPA & 0.5484 & 2.6558 & 0.2065 & Side 1 \\
\hline $\begin{array}{l}\text { DP486- } \\
0406005\end{array}$ & Crystal 21 & $\begin{array}{l}\text { Center of } \\
\text { crystal }\end{array}$ & DSPA & 0.549 & 2.6717 & 0.2055 & Side 1 \\
\hline $\begin{array}{l}\text { DP486- } \\
0406006\end{array}$ & Crystal 27 & $\begin{array}{l}\text { Center of } \\
\text { crystal }\end{array}$ & DSPA & 0.5485 & 2.6673 & 0.2056 & Side 1 \\
\hline $\begin{array}{l}\text { DP486- } \\
0406007\end{array}$ & Crystal 03 & $\begin{array}{l}\text { Center of } \\
\text { crystal }\end{array}$ & DSPA & 0.5479 & 2.6544 & 0.2064 & Side 2 \\
\hline $\begin{array}{l}\text { DP486- } \\
0406008\end{array}$ & Crystal 13 & $\begin{array}{l}\text { Center of } \\
\text { crystal }\end{array}$ & DSPA & 0.5491 & 2.6684 & 0.2058 & Side 2 \\
\hline $\begin{array}{l}\text { DP486- } \\
0406009\end{array}$ & Crystal 21 & $\begin{array}{l}\text { Center of } \\
\text { crystal }\end{array}$ & DSPA & 0.5513 & 2.6948 & 0.2046 & Side 2 \\
\hline $\begin{array}{l}\text { DP486- } \\
0406010\end{array}$ & Crystal 27 & $\begin{array}{l}\text { Center of } \\
\text { crystal }\end{array}$ & DSPA & 0.5493 & 2.6745 & 0.2054 & Side 2 \\
\hline $\begin{array}{l}\text { DP486- } \\
0406011\end{array}$ & Crystal 03 & $\begin{array}{l}\text { Center of } \\
\text { crystal }\end{array}$ & DSPA & 0.5488 & 2.6593 & 0.2064 & Side 1 \\
\hline $\begin{array}{l}\text { DP486- } \\
0406012\end{array}$ & Crystal 27 & $\begin{array}{l}\text { Center of } \\
\text { crystal }\end{array}$ & DSPA & 0.548 & 2.6524 & 0.2066 & Side 2 \\
\hline $\begin{array}{l}\text { DP486- } \\
0406013\end{array}$ & Crystal 27 & $\begin{array}{l}\text { Center of } \\
\text { crystal }\end{array}$ & DSPA & 0.549 & 2.6706 & 0.2056 & Side 2 \\
\hline $\begin{array}{l}\text { DP486- } \\
0425002\end{array}$ & $\begin{array}{l}\text { Crystal } 03 \text { - } \\
\text { Side } 1\end{array}$ & $\begin{array}{l}\text { Center of } \\
\text { crystal }\end{array}$ & DSPA & 0.5493 & 2.6696 & 0.2058 & \\
\hline $\begin{array}{l}\text { DP486- } \\
0425003\end{array}$ & $\begin{array}{l}\text { Crystal } 21 \text { - } \\
\text { Side } 1\end{array}$ & $\begin{array}{l}\text { Center of } \\
\text { crystal }\end{array}$ & DSPA & 0.5511 & 2.7102 & 0.2034 & \\
\hline $\begin{array}{l}\text { DP486- } \\
0425004\end{array}$ & $\begin{array}{l}\text { Crystal } 27 \text { - } \\
\text { Side } 1\end{array}$ & $\begin{array}{l}\text { Center of } \\
\text { crystal }\end{array}$ & DSPA & 0.5492 & 2.6782 & 0.2051 & \\
\hline $\begin{array}{l}\text { DP486- } \\
0425005\end{array}$ & $\begin{array}{l}\text { Crystal } 03 \text { - } \\
\text { Side } 2\end{array}$ & $\begin{array}{l}\text { Center of } \\
\text { crystal }\end{array}$ & DSPA & 0.5488 & 2.6767 & 0.205 & \\
\hline $\begin{array}{l}\text { DP486- } \\
0425006\end{array}$ & $\begin{array}{l}\text { Crystal } 21 \text { - } \\
\text { Side } 2\end{array}$ & $\begin{array}{l}\text { Center of } \\
\text { crystal }\end{array}$ & DSPA & 0.5493 & 2.6818 & 0.2048 & \\
\hline $\begin{array}{l}\text { DP486- } \\
0425007\end{array}$ & $\begin{array}{l}\text { Crystal } 27 \text { - } \\
\text { Side } 2\end{array}$ & $\begin{array}{l}\text { Center of } \\
\text { crystal }\end{array}$ & DSPA & 0.5484 & 2.6543 & 0.2066 & \\
\hline $\begin{array}{l}\text { DP486- } \\
0504002^{a}\end{array}$ & $\begin{array}{l}\text { EV Products } \\
\text { crystal } 21\end{array}$ & Side 1 & DSPA & 0.5507 & 2.6977 & 0.2041 & $\begin{array}{l}\text { Gross count } \\
\text { rate }= \\
7800 \mathrm{cps}\end{array}$ \\
\hline $\begin{array}{l}\text { DP486- } \\
0504003\end{array}$ & $\begin{array}{l}\text { EV Products } \\
\text { crystal } 21\end{array}$ & Side 2 & DSPA & 0.5485 & 2.652 & 0.2068 & $\begin{array}{l}\text { Gross count } \\
\text { rate }= \\
8500 \mathrm{cps}\end{array}$ \\
\hline $\begin{array}{l}\text { DP486- } \\
0504004^{\mathrm{a}}\end{array}$ & $\begin{array}{l}\text { EV Products } \\
\text { crystal } 21\end{array}$ & Side 2 & DSPA & 0.5519 & 2.7067 & 0.2039 & $\begin{array}{l}\text { Gross count } \\
\text { rate }= \\
7800 \mathrm{cps}\end{array}$ \\
\hline
\end{tabular}


Table B-4. EV products CZT crystal PIPA measurement results.

\begin{tabular}{|l|l|l|l|c|c|c|c|}
\hline $\begin{array}{c}\text { Spectrum } \\
\text { ID }\end{array}$ & $\begin{array}{c}\text { Sample } \\
\text { Description }\end{array}$ & Location & Analysis & $\begin{array}{c}\text { S } \\
\text { Parameter }\end{array}$ & $\begin{array}{c}\text { S/W } \\
\text { Ratio }\end{array}$ & $\begin{array}{c}\text { W } \\
\text { Parameter }\end{array}$ & Comments \\
\hline $\begin{array}{l}\text { DP486- } \\
0406014\end{array}$ & Crystal 13 & $\begin{array}{l}\text { Center of } \\
\text { crystal }\end{array}$ & PIPA & 0.5515 & 2.7214 & 0.202651 & Broken \\
\hline $\begin{array}{l}\text { DP486- } \\
0406015\end{array}$ & Crystal 21 & $\begin{array}{l}\text { Center of } \\
\text { crystal }\end{array}$ & PIPA & 0.5537 & 2.7725 & 0.199699 & \\
\hline $\begin{array}{l}\text { DP486- } \\
0407003\end{array}$ & Crystal 03 & $\begin{array}{l}\text { Center of } \\
\text { crystal }\end{array}$ & PIPA & 0.5522 & 2.7609 & 0.2 & \\
\hline $\begin{array}{l}\text { DP486- } \\
0407004\end{array}$ & Crystal 27 & $\begin{array}{l}\text { Center of } \\
\text { crystal }\end{array}$ & PIPA & 0.5506 & 2.7175 & 0.2026 & \\
\hline $\begin{array}{l}\text { DP486- } \\
0426002\end{array}$ & Crystal 03 & $\begin{array}{l}\text { Center of } \\
\text { crystal }\end{array}$ & PIPA & 0.5526 & 2.7589 & 0.2003 & \\
\hline $\begin{array}{l}\text { DP486- } \\
0426003\end{array}$ & Crystal 21 & $\begin{array}{l}\text { Center of } \\
\text { crystal }\end{array}$ & PIPA & 0.5534 & 2.7642 & 0.2002 & \\
\hline $\begin{array}{l}\text { DP486- } \\
0426004\end{array}$ & Crystal 27 & $\begin{array}{l}\text { Center of } \\
\text { crystal }\end{array}$ & PIPA & 0.5515 & 2.7427 & 0.2011 & \\
\hline $\begin{array}{l}\text { DP486- } \\
0504005\end{array}$ & $\begin{array}{l}\text { EV Products } \\
\text { crystal 13 }\end{array}$ & $\begin{array}{l}\text { Center of } \\
\text { crystal }\end{array}$ & PIPA & 0.5528 & 2.7542 & 0.200695 & Broken \\
\hline $\begin{array}{l}\text { DP486- } \\
0504006\end{array}$ & $\begin{array}{l}\text { EV Products } \\
\text { crystal 27 }\end{array}$ & $\begin{array}{l}\text { Center of } \\
\text { crystal }\end{array}$ & PIPA & 0.5498 & 2.7059 & 0.20317 & \\
\hline
\end{tabular}

